\title{
PLC-BASEd Adaptive Relay Protection SYSTEM IMPLEMENTATION
}

\author{
Ualikhan Iskakov, Josif Breido \& Gamzat Sundet
}
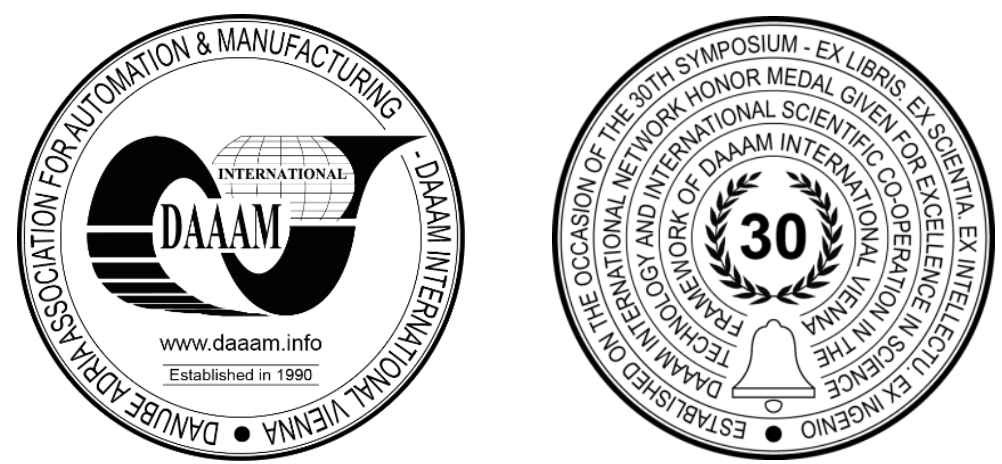

This Publication has to be referred as: Iskakov, U[alikhan]; Breido, J[osif] \& Sundet, G[amzat] (2020). PLC-Based Adaptive Relay Protection System Implementation, Proceedings of the 31st DAAAM International Symposium, pp.01280136, B. Katalinic (Ed.), Published by DAAAM International, ISBN 978-3-902734-29-7, ISSN 1726-9679, Vienna, Austria

DOI: $10.2507 / 31$ st.daaam.proceedings.017

\begin{abstract}
The article describes the processes of implementation and experimental testing of the system for adapting the relay protection settings to changes in the network voltage. The adaptation system implemented based on the PLC and a microprocessor current protection device. The article describes the stages of development of a test bench, development of a methodology and testing program, and presents the test results. The purpose of the experimental study: experimental confirmation of the effectiveness of the developed adaptation system of the current protection settings when the voltage fluctuates within the permissible limits. According to the results of experimental studies, the developed adaptation system significantly increases the reliability of operation of relay protection, in case of network faults that occurred at the time of voltage fluctuations within the permissible and maximum permissible limits. The adaptation system prevents nonselective tripping both when the mains voltage drops and when it rises.
\end{abstract}

Keywords: PLC; relay protection; adaptation; selectivity; test bench.

\section{Introduction}

Modern microprocessor based relay protection devices in comparison with their analog alternatives, have significant advantages, such as more accurate selection of the fundamental current harmonics by filtration means, functional advantages due to the use of efficient microprocessors and the possibility of self-diagnostics [1]. However, all these facts do not lead to a significant improvement in the speed of operation, selectivity and sensitivity of relay protection systems. The main problem is that relay protection systems must be adaptive to changing network parameters. Adaptability should be one of the main requirements for relay protection along with speed of operation, selectivity.

Adaptive relay protection is an extremely important area, which has resulted from the integration of digital protection devices, intelligent electronic devices and communication systems. This allows adjusting the relay settings in response to changing network conditions to maintain optimal performance. Microprocessor based relay protection is a tool to implement the concept of adaptive protection [2], [3]. The most of related to adaptive relay protection papers are aimed at solving the problems of adaptation in power systems with distributed generation [4], [5], [6], [7], [8], [9]. However, there are no works devoted to the adaptation of current protection to voltage changes in the network. 
One of the common situations that lead to non-selective operation of relay protection it is voltage fluctuations in the mining industry, where there are loads with big consumptions: mills, hoisting equipment, main conveyors, etc. As an example, a voltage dips leads to relay protection devices failure to actuate during faults in the protected zone, and overvoltage leads to non-selective tripping (unnecessary trip) during disturbances outside of the protected zone. [9]

In the electric systems with short protected zones (up to $2 \mathrm{~km}$ ), the normally acceptable and maximum permissible voltage fluctuations lead to significant changes in parameters that affect the choice of characteristics and settings of relay protection. Due to the small difference in the total inductive resistance of the upstream and downstream protective zones in distribution cable networks, voltage fluctuations lead to non-selective operation of protection. [10], [11]. Therefore, the development of a system for adapting relay protection to voltage changes is an important and priority research area.

\section{PLC-based adaptive relay protection system implementation}

In the works previously published by the author, the process of developing a network model with an isolated neutral, a current protection model, and a setting adaptation model described, as well as the simulation results [10], [11], [12], [13]. The obtained results of the study formed the basis for the proposed algorithm for the operation of the adaptation system prototype presented in Fig. 1.

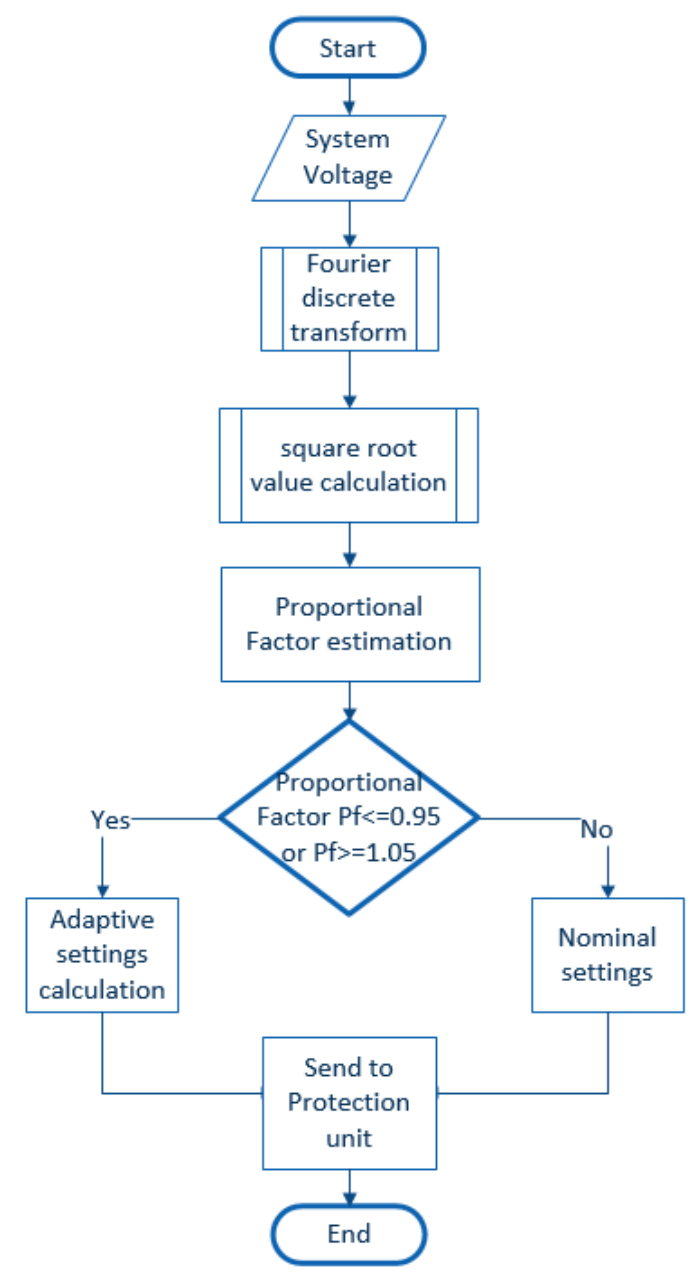

Fig. 1. Algorithm of settings adaptation system

The adaptation system should solve the following tasks:

- Collection of measuring data from relay protection devices or converting devices about the state of network parameters;

- Calculation of the variation degree of controlled parameters;

- Calculation of adaptive settings;

- Transfer of adaptive settings to relay protection devices.

To implement all of the above functions, the adaptation system must have sufficient computing power to ensure a sufficiently high polling rate and adaptation of the protection settings, which can be reached in one of two ways:

- Using the computing power of microprocessors built into protection devices;

- Using of external computing processors (personal computer, programmable logic controller). 
The difficulty of implementing adaptive system using the computing power of microprocessors built into protection devices is associated with the closed software architecture (closed source code) of microprocessor based relay protection devices.

The hardware capabilities of modern microprocessor-based protection devices allow implementing the proposed adaptation algorithm and providing the required level of accuracy and speed. The adaptation algorithm should be preinstalled during manufacturing in the read only memory of the protection terminal, due to the closed source code the adaptation algorithm cannot be installed using any programming device or programming software. Some microprocessorbased relay protection devices have internal logic editors. Logic Equation Editor an editor program that adapts standard control functions to various special applications by programming the required additional functions. The feature of such editors is limited only by the functions of controlling the output relays, LEDs, oscillography triggering and alarm outputs. Such a set of feature does not allow realizing proposed the settings adaptation algorithm. The present-day situation in the field of microprocessor-based overcurrent protection devices makes it necessary to implement settings adaptation system using external computing devices. Modern programmable logic controllers (PLCs) can serve as such devices.

Taking into account the peculiarities of modern microprocessor-based relay protection devices, we propose a structural diagram shown in Fig. 2 to implement PLC based adaptive protection system.

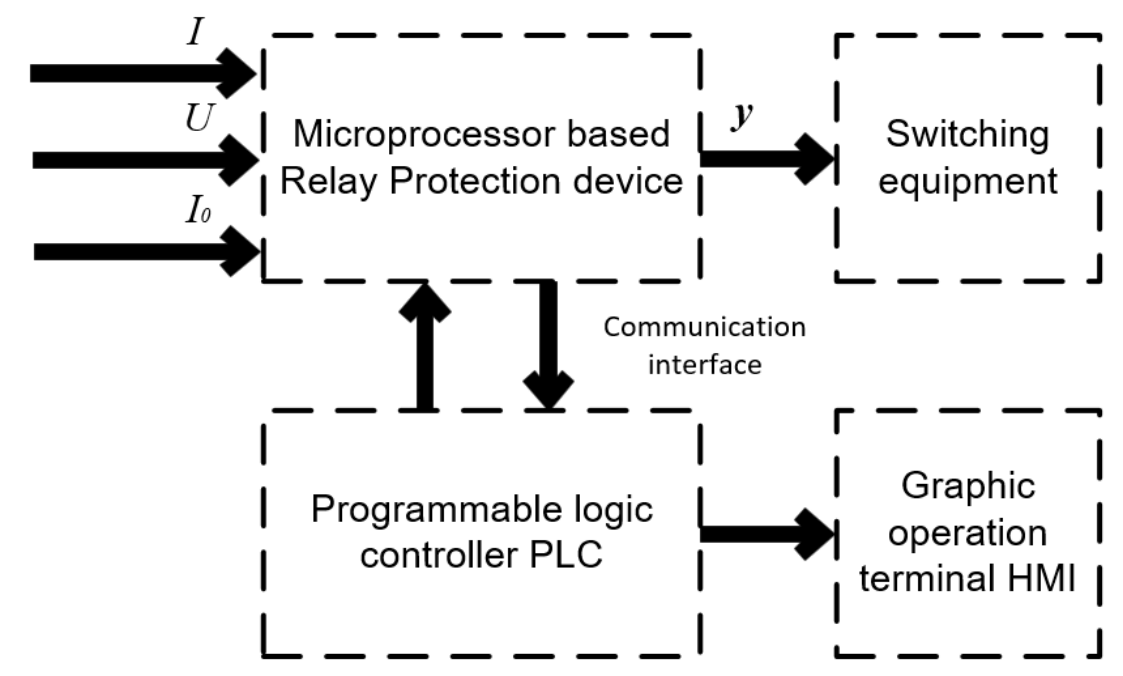

Fig. 2. Structural diagram of PLC based adaptive system

According to the proposed structural diagram, the signals of currents and voltages of the monitored network transmit through intermediate measuring transducers to the microprocessor protection device. The relay protection device transmits the network state data to the PLC via communication interfaces. The PLC recalculates the adapted to the voltages change current protection settings, and transfers it back to the relay protection device.

Electrical network parameters, parameters characterizing the variation degree of voltage, settings calculated for nominal values, as well as adapted protection settings displayed on a graphic operation terminal HMI. The graphic operation terminal HMI records the controlled parameters in a form convenient for their further analysis and processing.

\section{Selection of the components of PLC based settings adaptation system}

Microprocessor-based overcurrent protection devices are a class of relay protection devices combining only a basic set of overcurrent protections such as instantaneous overcurrent protection, overcurrent with time delay and earth fault protection. There are a large number of different devices on the relay protection device market, both from large manufacturers, such as Siemens, Schneider Electric, Micom, Alstom, ABB, and less well-known but producing sufficiently high-quality products such as FANOX, Microelettrica Scientifica, Mechanotronika and others.

To implement the proposed system, a relay protection device with ability to remotely change the settings using communication interfaces is required, since settings are often available only for reading. It is also desirable to have analog voltage inputs for transmitting data about the network parameters to the PLC.

Among a large number of possible options, we have chosen a digital device for phase-to-phase and single-phase faults Micom P111. Micom P111 - has a number of characteristics that allow the most complete implementation of the proposed algorithm:

- Set of only the most necessary functions of overcurrent protection, which facilitates the process of setting configuration of protection devices;

- Clear and accessible structure of the organization of data exchange via communication interfaces;

- Availability both for reading and for writing of protection settings via the communication interfaces. 
Due to the orientation of the Micom P111 terminal only on the implementation of basic current protection, the device does not have analog inputs for measuring the mains voltage. To monitor the mains voltage, a multifunctional electronic measuring instrument ME96SSR-MB manufactured by Mitsubishi was selected. ME96SSR-MB measures all the main network parameters using measuring transformers, displays the measurements on the liquid crystal display.

The PLC is the basic part of the proposed current protection adaptation system. The adaptation algorithm implemented by using the program uploaded into the PLC memory. The basic module and communication modules of the Mitsubishi Electric FX3U 16MR / ES PLC series selected to implement the system. The FX3U PLC concept allows the industrial controller to configuring exactly the way it is needed for the task. The graphic operator panel GOT 1000 series manufactured by Mitsubishi Electric selected to visualize the adaptation process.

\section{PLC program development}

The PLC operates according to a predefined program. A program consists of a series of individual control instructions that define control functions. The PLC processes the control instructions in accordance with the programmed sequence one after the other, i.e. sequentially. Therefore, to produce a control program, the control process itself must be split into separate instructions.

The PLC programs are written in specialized development environments using programming languages standardized by the International Electrotechnical Commission standard IEC 61131-3 [Error! Reference source not found.4], [15]. The GC IEC Developer used as PLC programming software. The developed PLC program consists of two program modules: MAIN_PRG_LD and Data Ch2. The program module (PM) MAIN_PRG_LD implements the basic functions of the adaptation algorithm and is the basis of the program. PM Data Ch2 is a subroutine that adjusts the parameters of the data exchange interface module and checks the integrity of data during their transfer and storage (check the CRC sum). The PLC program development window for the adaptation system shown in Fig. 3.

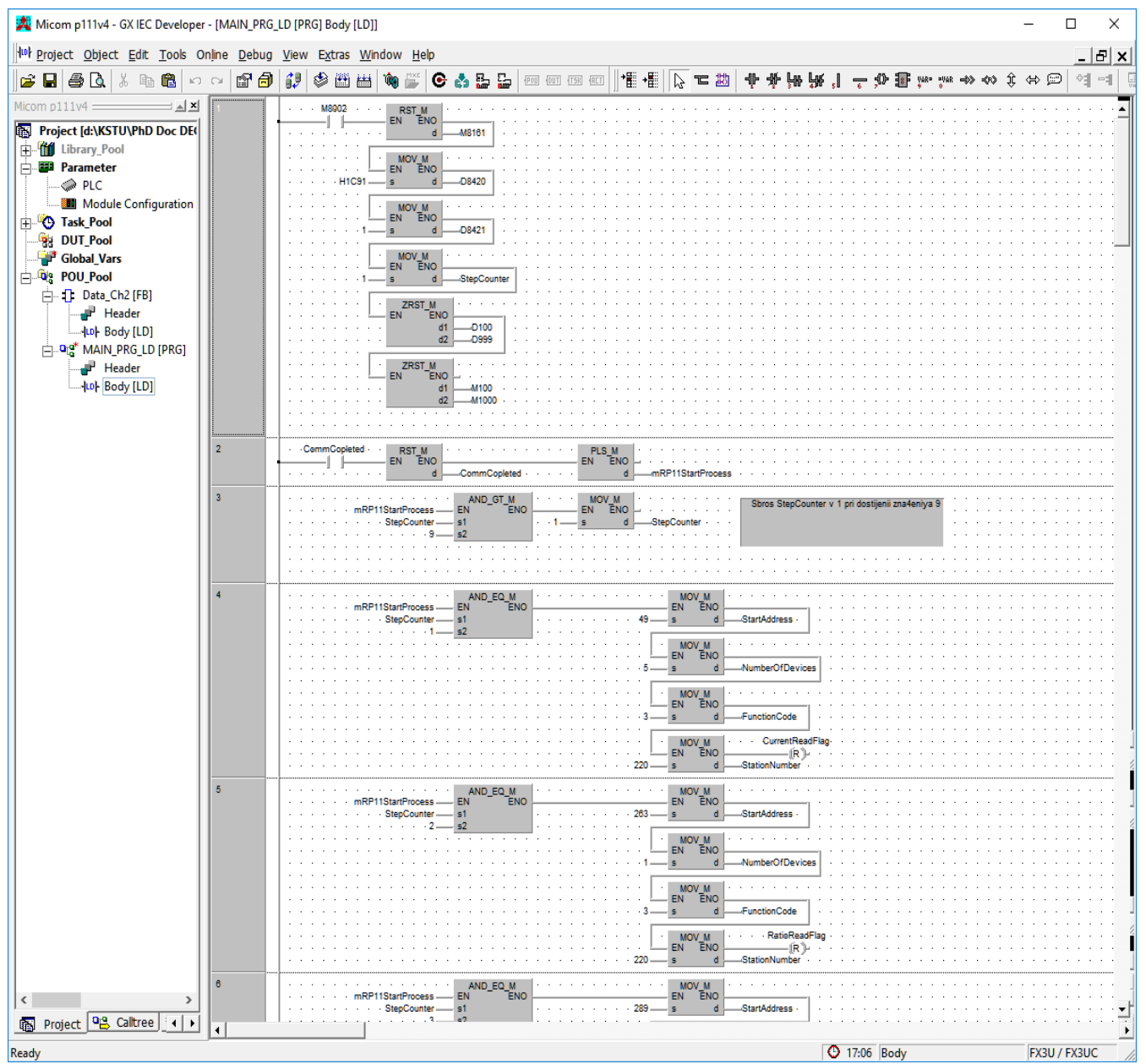

Fig. 3. PLC program development window for the adaptation system.

The PLC program of the system for adapting the current protection settings implemented in accordance with the developed algorithm. The program written in the LD (Ladder Diagram) and FBD (Function Block Diagram) programming languages. 
Before starting the developed system, it is necessary to configure its parameters. The user enters the trip settings calculated for nominal conditions and the nominal value of the mains voltage into the PLC memory, using a graphic operator panel or a personal computer. Then the developed program performs the following sequence of actions:

- Using the communication module of the serial interface Modbus 485 - FX3U - 485ADP-MB, the PLC interrogates the ME96 multifunctional electronic measuring instrument, with the help of which the changing values of the mains voltage recorded.

- The load values and the current values of the pickup settings read from the Micom P111 digital current protection device, and written into the PLC memory. Analog values of voltage and currents entering the PLC do not require additional digital filtering and sampling, since the measuring instrument ME96 and the digital protection device Micom P111 carry out these processes.

- The PLC compares the voltage RMS value with the nominal value and calculates a proportionality factor reflecting the voltage variation degree. The obtained proportionality coefficient compared with the threshold values determined by the dead band of the adaptation system. If the proportionality factor goes beyond the limits determined by the dead band, the protection settings recalculated.

- The recalculated settings transferred back to the Micom p111. After the return of the mains voltage values within the limits at which no adaptation of the pickup settings is required, the nominal settings transferred to the protection devices.

For the further process of visualization and control, the program of the graphic operator panel GOT 1000 was developed. Fig. 4 shows the general window of the graphic operator panel. The window of the graphic operator panel shows all the necessary information characterizing the process of adapting the protection settings. Using the panel, you can set the nominal protection settings and nominal voltage of the monitored network, there is a button on the panel that enables the adaptation process.

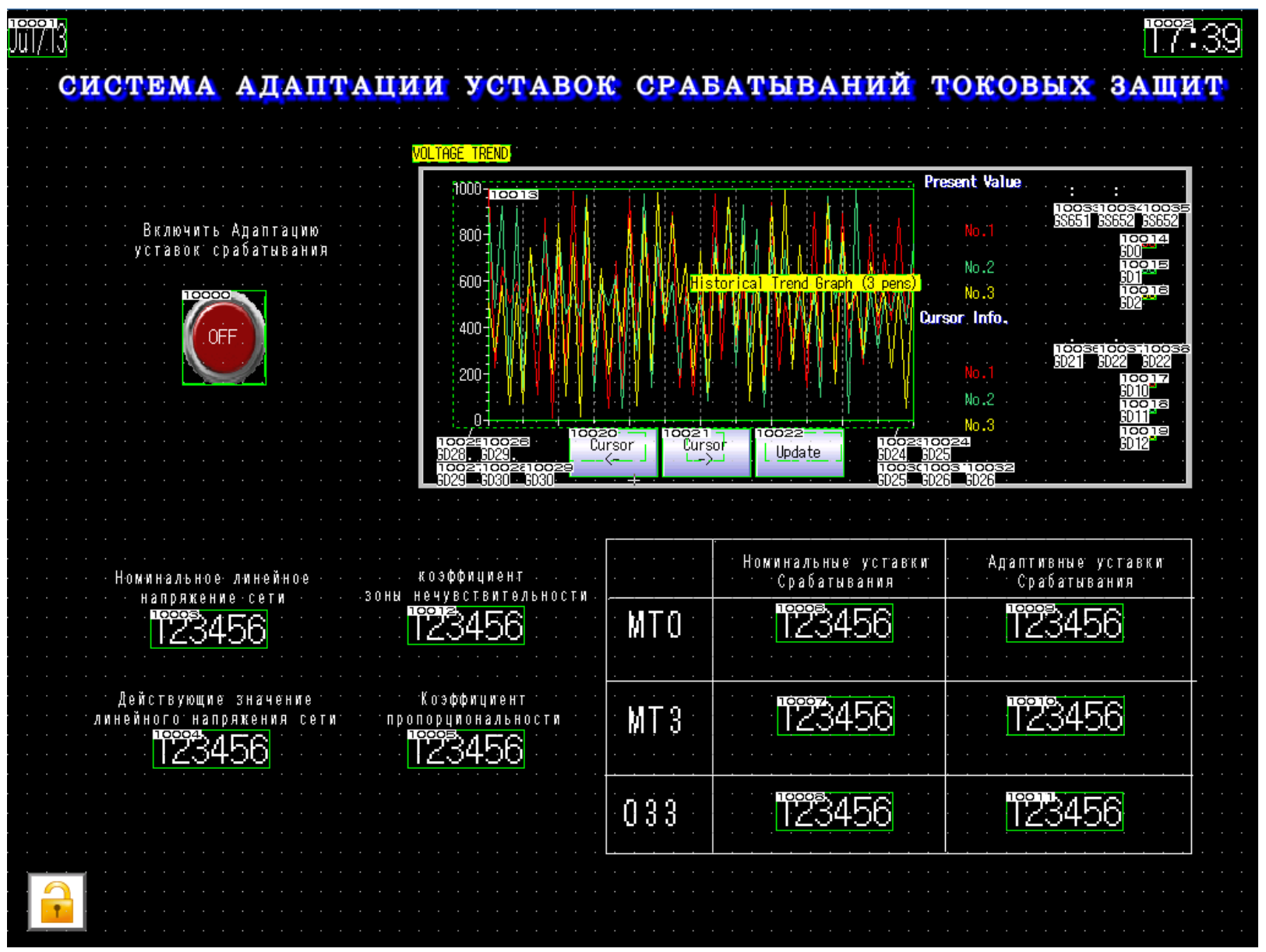

Fig. 4. The main window of the graphic operator panel of the system for adapting the protection settings

The panel displays the nominal and adaptive pickup settings, the mains voltage, and the proportionality factor, which reflects degree of voltage change from the nominal value. Trip signals from relay protection device recorded and shown on main window. All of the above information is useful for analyzing the effectiveness of the system for adapting the settings of the current protection operation. 


\section{Testing bench of protection settings adaptation system}

Test bench of the protection settings adaptation system must perform two main functions:

- Imitation of processes taking place in the controlled network;

- Registration of the research process data.

Test bench of the protection settings adaptation system should be able to record the following parameters:

- RMS voltage value of the monitored network and the level of its deviation from the nominal value;

- Values of the current protection device pickup settings;

- Response time of overcurrent protection devices.

The relay protection test set used to simulate the processes occurring in the power grid both during the nominal operating mode and during the occurrence of faults.

According to the proposed structural diagram of test bench of adaptation system, the relay protection test set generates analog values of the network parameters and must meet the following requirements:

- Generation of independently regulated three-phase voltage;

- Generation of independently regulated three-phase currents and zero sequence current;

- Measuring the time characteristics of relay protection devices;

- Measuring the magnitude of direct and alternating current;

- Measuring the value of direct and alternating voltage;

- Oscillography of current and voltage.

RETOM-61 relay test set produced by SPE "Dynamics" chosen to test the proposed adaptation system. The diagram of the test bench of the adaptation system presented in Fig. 5.

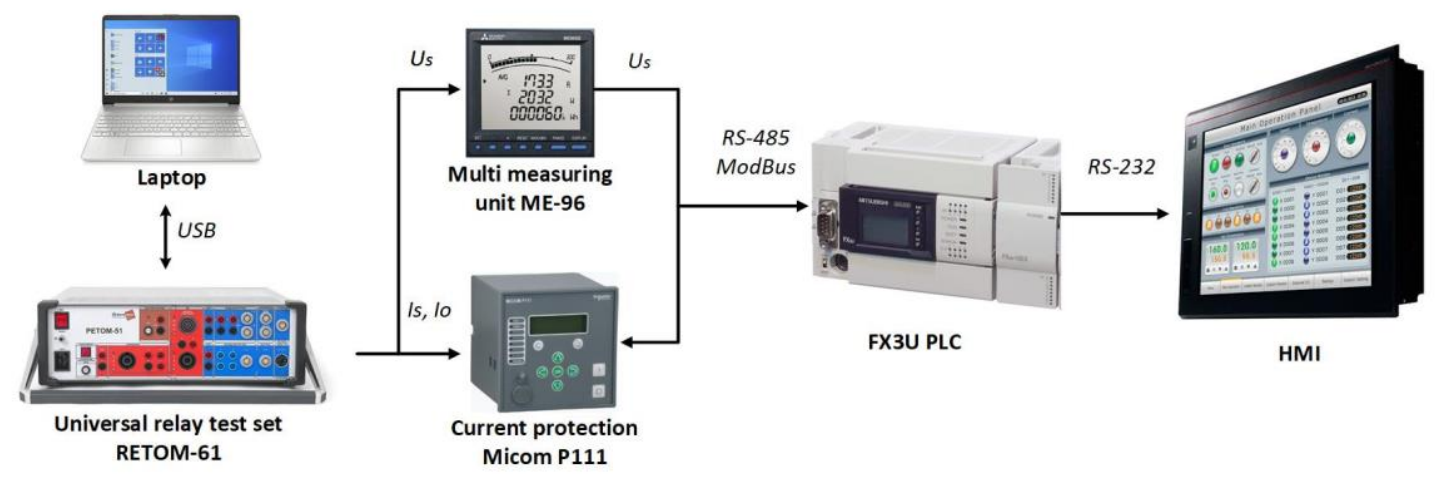

Fig. 5. The diagram of the test bench of the adaptation system

The graphical operator panel and measuring capabilities of the relay protection test set provide monitoring and registration of controlled network parameters required for analyzing the effectiveness of the developed adaptation system. The test set registers tripping of the relay protection device via discrete inputs to analyze the speed of the adaptation system.

\section{The testing of adaptation system test bench}

The limitations of the research and the author's approach. Testing research do not does not take into account load current impact.

The methodology of testing of PLC based settings adaptation system test bench was proposed. The testing methodology includes the following main stages:

- Development of testing program;

- Evaluation of measurements and selection of means for conducting the experiment;

- Testing;

- Processing and analysis of test result data

When the mains voltage goes beyond a certain range, outside of which the parameters that affect the choice of protection settings are significantly changed, the adaptation system should automatically recalculate the settings in accordance with the mains voltage value.

For such systems, it is necessary to conduct an experiment not only in the zone of the intended action of the system, but also in the zone of its normal functioning, as well as very important observation of the action of the system after returning from the zone of action to the zone of normal functioning. 
The testing program. The sequence of the operations of measurements and observations:

- Set the nominal values of the operation settings and network parameters;

- Change voltage in the range from $-15 \%$ to plus $15 \%$ percent, registration of controlled values;

- Registering protection device tripping at adaptive actuation settings.

The setting of the nominal values of the protection settings and the network parameters provided using the operator panel or PC, which is associated with the peculiarity of the program algorithm. Setting the nominal voltage value of the monitored network is necessary to control the change in the network voltage. The voltage change of the monitored network provided by RETOM-61 relay test set. Voltage supplied to the ME96SSR-MB multifunctional measuring device from the analog outputs of RETOM-61. The applied voltage will range from $85 \mathrm{~V}$ to $115 \mathrm{~V}$, which will correspond to a change from $-15 \%$ to $+15 \%$ of the nominal value in $1 \%$ steps. With each voltage change from the operator panel and from the relay protection device itself, the response settings are fixed. All data recorded in the observation log.

Verification of protection device tripping at adaptive settings. Tripping currents injected to the protection device using the RETOM-61 relay protection test set. The pickup setpoints calculated for the network nominal values are freely selectable. To reduce the number of test points, the tripping checked only for two overcurrent protection steps instantaneous overcurrent protection and overcurrent with time delay. The operate currents, as well as the voltage, vary within the range from $-15 \%$ to $+15 \%$ of the nominal value in $1 \%$ steps, and are supplied to the overcurrent protection device both with voltage changes and without voltage changes. Operations of protection and settings recorded in the observation log. The speed of the adaptation system fixed by measuring the time from the moment of voltage change to recalculation of the protection settings

The program of the graphic operator panel records in graphical form the operating voltage of the network, the protection settings, the protection device tripping time, and the current of the controlled network. The purpose of testing: Experimental confirmation of the effectiveness of the developed protection settings adaptation system when the voltage fluctuates within the permissible limits. Experimental research objectives:

- Assessment of the accuracy and reliability of the algorithm for adapting the response settings;

- Measuring the operation speed of the protection settings adaptation system.

A number of experiments were carried out in order to confirm the compliance of the proposed method of PLC based adapting of the current protection settings to the requirements of reliability, speed and increase in selectivity with voltage fluctuations within acceptable limits. The PLC based settings adaptation test bench presented in Fig. 6.

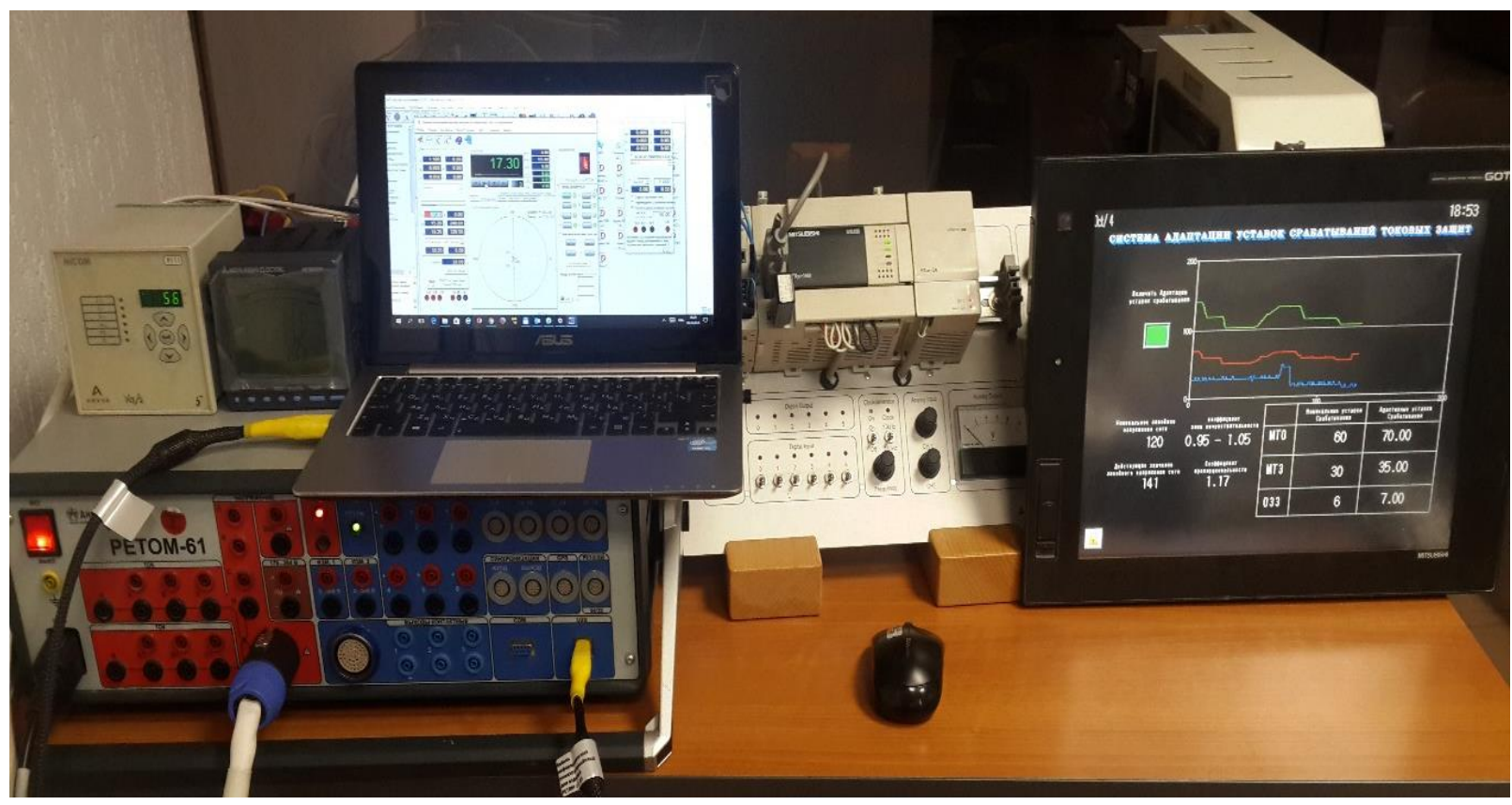

Fig. 6. PLC based settings adaptation system and relay protection test set RETOM-61

The graphical operator panel shown on Fig. 7. The panel displays:

- The nominal and adaptive pickup settings;

- The nominal and real mains voltage:

- The proportionality factor;

- The dead band range;

- The trends of current and voltage and trip signal. 


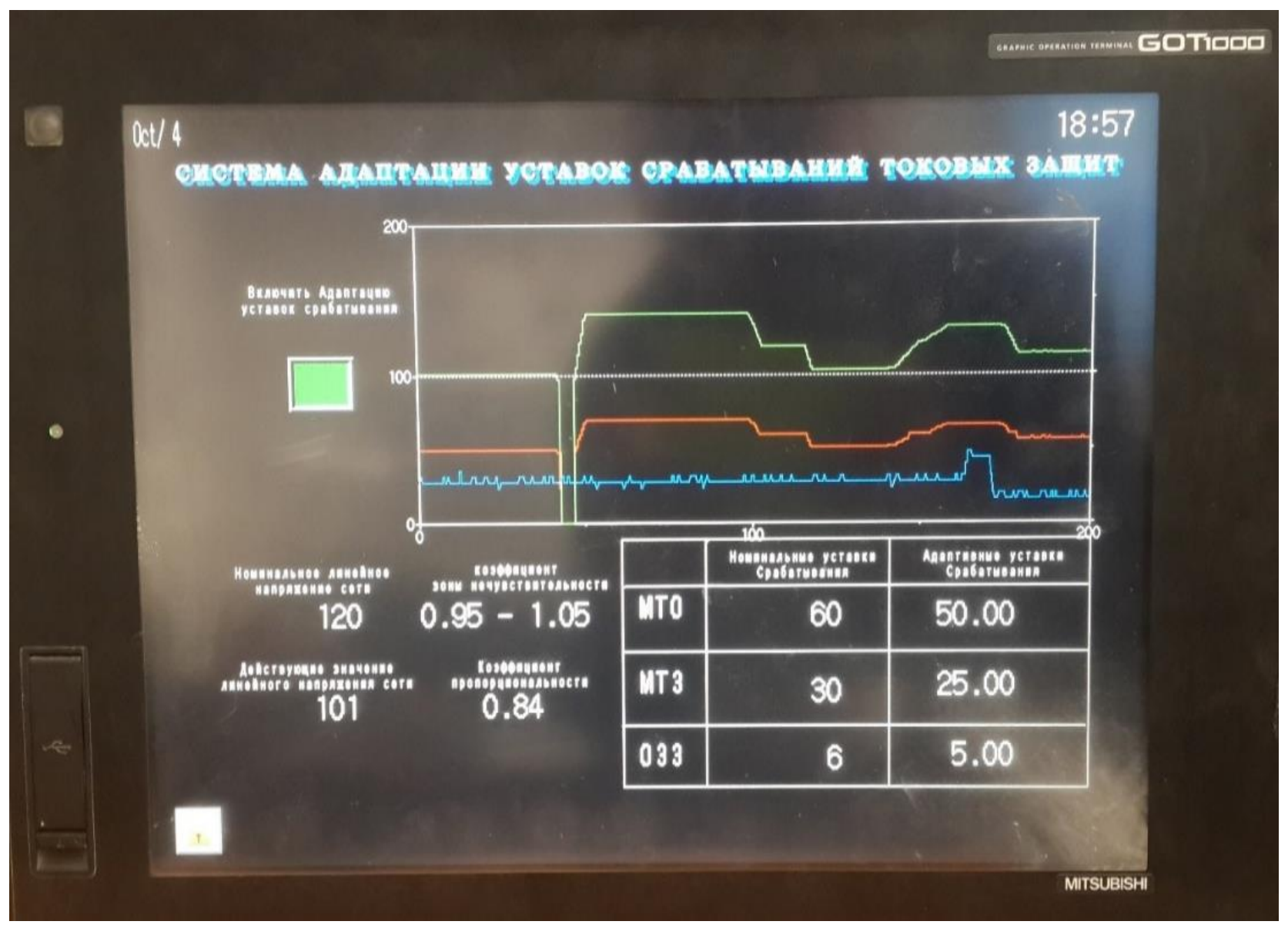

Fig. 7. Graphical operator panel displays trends of currents and voltage of electrical network, and trend of adapted setting of relay protection

Table 1 contains nominal values specified in the experimental studies of PLC based settings adaptation test bench. Table 2 shows the results of the experimental studies.

\begin{tabular}{|c|c|}
\hline Settings & Value \\
\hline Instantaneous Overcurrent protection start current, A & 60 \\
\hline Overcurrent with time delay protection start current, $A$ & 30 \\
\hline Nominal Voltage, $\mathrm{V}$ & 120 \\
\hline The dead band range & $0,95-1,05$ \\
\hline
\end{tabular}

Table 1. Nominal settings used during testing

\begin{tabular}{|c|c|c|c|}
\hline RMS voltage, V & $\begin{array}{c}\text { Instantaneous Overcurrent } \\
\text { protection start current, A }\end{array}$ & $\begin{array}{c}\text { Overcurrent with time delay } \\
\text { protection start current, A }\end{array}$ & $\begin{array}{c}\text { The adaptation } \\
\text { speed, sec }\end{array}$ \\
\hline 85 & 51,2 & 17,1 & 0,4 \\
\hline 87 & 52,2 & 17,4 & 0,4 \\
\hline 89 & 53,4 & 17,8 & 0,4 \\
\hline 91 & 54,6 & 18,2 & 0,4 \\
\hline 93 & 55,8 & 18,6 & 0,4 \\
\hline 95 & 60 & 20 & 0,4 \\
\hline 99 & 60 & 20 & 0,4 \\
\hline 105 & 60 & 20 & 0,4 \\
\hline 107 & 64,2 & 21,4 & 0,4 \\
\hline 111 & 66,5 & 22,1 & 0,4 \\
\hline 113 & 67,8 & 22,6 & 0,4 \\
\hline
\end{tabular}

Table 2. The results of the experimental studies 
According to the presented results of experimental studies, the developed PLC based settings adaptation system works in accordance with the developed operation algorithm. The adaptation speed, measured by internal timers of the GX IEC Developer programming environment, and obtained as a result of the analysis of graphs from the operator panel, is no more than 0.4 seconds. The adaptation speed time depends of PLC program cycle duration. The settings adjusted when the mains voltage goes beyond the dead band. The accuracy of the calculated adaptive pickup settings within 0 to $2 \%$, which is due to the error of the measuring instruments used.

\section{Conclusion}

The authors of the article were faced with the task of implementing a system for adapting current protection and provide an experimental study to confirm the effectiveness of the proposed system. The task was solved by using modern PLC and microprocessor-based relay protection devices. The tests confirmed the main results of theoretical studies, the adequacy of mathematical models and simulation [10], [11], [12]. According to the results of the experimental studies, the developed system for adapting the settings of current protection significantly increases the reliability of the relay protection devices, in case of network faults that occurred at the time of voltage fluctuations within the permissible and maximum permissible limits. The adaptation system prevents non-selective operations both when the mains voltage drops and when it rises.

In the future, we are going to apply this system at local distribution dead-end substations with a small number of feeders, for the implementation of which it is necessary to use protection devices supporting faster data transfer interfaces such as Ethernet. There are also plans for joint work with manufacturers of relay protection devices to implement the proposed adaptation algorithm directly into the memory of microprocessor protection devices. Designers and specialists in the operation of relay protection devices can use the developed test bench of the adaptation system, the methodology and plan-program of experimental studies of the test bench of the adaptation system, in order to create adaptation systems for other types of overcurrent protection devices using PLCs of any manufacturer.

\section{References}

[1] Blackburn J.L., Domin T.J. (2006). Protective Relaying Principles and Applications. - Taylor \& Francis Group LLC, $-638 \mathrm{p}$.

[2] Aggarwal R., Johns A., Warwick K., Ekwue A.O., Aggarwal R. (1997). Artificial Intelligence Techniques in Power Systems. - London: Institution of Electrical Engineers, pp. 123-142.

[3] Codling J.D., House S.A., Joice J.H., Labhart K.M., Richards J.R., Tenbusch J.E. (1996). Adaptive relaying. A new direction in power system protection // Potentials IEE. Vol. 15, Is. 1, pp. 28-33.

[4] Mäki K. et al. (2005).Protection issues in planning of distribution network including distributed generation. - CIGRE Symposium: Power Systems with Dispersed Generation, pp. 1-5.

[5] Dugan R.C., McDermott T. E. (2002). Distributed Generation. IEEE Industry Applications Magazine. March/April, pp. $19-25$.

[6] Baran M., El-Markabi I. (2004). Adaptive Over Current Protection for Distribution Feeders with Distributed Generators // Proceedings Power Systems Conference and Exposition. - Vol. 2, pp. 715-719.

[7] Dugan R.C., McDermott T.E. (2001). Operating conflicts for distributed generation on distribution systems // Rural Electric Power Conference. - Little Rock, pp. A3/1-A3/6.

[8] Chen M.Z., Bak-Jensen B., Bak C.L. (2011). Simple Adaptive Overcurrent Protection of Distribution Systems With Distributed Generation // IEEE Transactions on Smart Grid. Vol. 2, No. 3, pp. 428-437.

[9] Jafari R., Naderi M.S., Gharehpetain G.B. (2014). An Adaptive Protection Scheme based on Fault Location for Smart Micro-Grids // International Conference on Renewable Energies and Power Quality. - Cordoba, pp. 1-5.

[10] U.K. Iskakov, J.V. Breido, K.K. Smagulova. (2016). Modeling of operating modes of the protection relays in isolated neutral system // Electrotechnica. № 10. ISSN: 0013-5860, pp. 45-49.

[11] Smagulova K.K., U. Iskakov (2017). Simulation Modes of relay protection devices in networks with insulated neutral, EAI Endorsed Transactions on Energy Web and Information Technology / Volume 4, Issue 15, e1.

[12] Iskakov U., Breido J. (2015). Settings Adaptation System for Current Protection Relay // 26th DAAAM International Symposium on Intelligent Manufacturing and Automation. - Zadar: Croatia, pp. 0371-0377

[13] U. Iskakov, J. Breido (2015). Development of control algorithm for adaptive leakage current protection devices' using Fuzzy logic, Procedia Engineering, Volume 100, pp 666-671

[14] International standard. IEC 61131-3. Second edition 2003-01. Programmable controllers - Part 3: Programming languages. - Geneva: Typeset and printed by the IEC Central Office, 2003.

[15] Lewis R.W. (1998). Programming industrial control systems using IEC 113-3 Revised edition. - London: The Institution of Electrical Engineers, 329 p. 